\title{
Prevalence and Risk Factors of Urinary/Anal Incontinence and Pelvic Organ Prolapse in Healthy Middle-Aged Iranian Women
}

\author{
Sevil Hakimi ${ }^{1}$, Elham Aminian ${ }^{2}$, Marzieh Mohammadi ${ }^{2}$, Sakineh Mohammad Alizadeh ${ }^{2}$, Parvin Bastani ${ }^{3}$, \\ Sousan Houshmandi ${ }^{4}$
}

${ }^{1}$ Research Center of Psychiatry and Behavioral Sciences, Tabriz University of Medical Science, ${ }^{2}$ School of Nursing and Midwifery, Department of Midwifery, Tabriz University of Medical Science, ${ }^{3}$ Women's Reproductive Health Research Center, Tabriz University of Medical Sciences, Tabriz, Iran, ${ }^{4}$ School of Nursing and Midwifery, Department of Midwifery, Ardabil University of Medical Science, Ardabil, Iran

Objectives: Urinary incontinence (UI) and anal incontinence (Al) cause concern, social exclusion, and ultimately reduced quality of life in women. The aim of present study was to assess the prevalence and related risk factors of $\mathrm{UI}, \mathrm{Al}$, and pelvic organ prolapse (POP).

Methods: The present study recruited 340 menopausal women living in Tabriz in northwest Iran. The data collection tools included the Pelvic Floor Distress Inventory-20 and a personal and social information questionnaire. POP was diagnosed via clinical examination using the simplified pelvic organ prolapse quantification system.

Results: The prevalence of UI and POP was approximately 50\%, and approximately $16 \%$ of participants reported Al. Based on the odds ratios, the most remarkable risk factor of urinary stress incontinence was the number of vaginal deliveries, whereas that of urinary urge incontinence was obesity. Episiotomy and age were the most major risk factors of Al and POP, respectively.

Conclusions: The results of the present study showed that the prevalence of POP, UI, and Al is remarkably high among postmenopausal women, warranting the need to prioritize the assessment of POP and various incontinences in middle-aged women in the primary health care system. Furthermore, increased emphasis should be put on modifiable risk factors.

Key Words: Fecal incontinence, Pelvic organ prolapse, Postmenopause, Urinary incontinence

\section{INTRODUCTION}

Pelvic organ prolapse (POP) is a common menopausal problem, which is defined as protrusion or projection of pelvic organs into or out of vagina. POP causes such problems as urinary, anal and gas incontinence [1]. Incontinence is a common health problem in societies and increases with aging [2]. Urinary incontinence (UI) refers to leakage of urine due to increased pelvic pressure as a result of coughing or sneezing, and also urgency in expulsion of urine [3]. Anal incontinence (AI) refers to the inability to control defecation or flatus [4]. Generally, UI and AI have common pathophysiology, as the prevalence of AI increases with increasing UI. Pelvic floor denervation during childbirth is the most prevalent pathophysiology of incontinence [5]. Many other social and personal factors, associated with UI and AI, including aging and parity, menopause, obesity, diabetes, chronic constipation, hypertension, occupational stressors, smoking, and genetic factors [6,7].

UI and AI causes concern, social exclusion, and ultimately affect quality of life in negative way [8]. In their

Received: May 10, 2019 Revised: August 19, 2019 Accepted: February 17, 2020

Address for Correspondence: Sevil Hakimi, Research Center of Psychiatry and Behavioral Sciences, Tabriz University of Medical Science, Shariati Street, Tabriz 51368, Iran

Tel: 98-9126035672, E-mail: hakimis@tbzmed.ac.ir, ORCID: https://orcid.org/0000-0002-3164-4867

This manuscript is extracted of Elham Aminian's MSc thesis from Tabriz University of Medical Science. 
study, Yip et al. [9] showed that incontinence is significantly associated with feeling of isolation and anxiety in older women, while women often refrain from expressing their AI due to fear or embarrassment [10]. In addition to the pain, it incurs living cost such as daily use of pads or medical cost for diagnosis and treatment for incontinence [2].

A review study has reported the prevalence of UI as between $7 \%$ to $30.3 \%$, based on self-report in various countries in women older than 40 years [2]. The main cause of UI is weakness of neuromuscular system in advanced ages [11]. In a study conducted by Demir et al. [12] on women older than 60 years in Turkey, the prevalence of AI was reported $10.2 \%$. They also reported the prevalence of mixed UI-AI 7.4\%.

POP has strong correlation with incontinence. Owing to different measurement systems and different definition, prevalence of POP among different societies is not consistent. Prevalence of symptom base POP among Emirati women estimated $26.9 \%$ by Elbiss et al. [13]. While Horst et al. [14] showed that prevalence of POP with using of pelvic organ prolapse quantification (POP-Q) measurement system is more than $50 \%$.

Due to different prevalence and risk factors extracted from different studies, the present study aimed to assessment prevalence and defining risk factor of UI/AI as well as POP among healthy postmenopausal women.

\section{MATERIALS AND METHODS}

\section{Study design and participants}

This was a cross-sectional population base study. Study population consisted of menopausal women living in the city of Tabriz, North-west Iran. Following approval by the ethics committee of Tabriz University of Medical Sciences (with ethic code: 5.4.4976), sampling was started. The sampling method was multi stage random sampling. In the first stage, we randomly selected 11 health centers out of 33 urban health centers existed in Tabriz. In the second stage, using records of households in each center, eligible women were identified, of whom, suitable proportion was randomly selected.

In line with international consistence society criteria, stress incontinence (SI) was defied to involuntary urine leakage during sneezing, coughing or laughing as well, urgent leak of urine considered as urinary urgency incontinence (UUI) [3]. AI refers to involuntary defecation and expulsion of flatus [4].

Inclusion criteria were naturally menopaused women aged between 45 and 60 years old and having no metal retardation. A urine sample was taken from all participants to rule out urinary infection. Women with more than three white blood cells in mid-stream urine sample were considered ineligible. Written informed consent was obtained from women willing to take part.

\section{Sample size}

Using Terauchi et al.'s study [15], and given the prevalence of SI 35\% among menopausal women, considering $\alpha=0.05, \beta=0.2$ and $d=0.05$, and ultimate sample size was determined 340 women.

\section{Data collection}

Data collection tools included demographic, and medical/midwifery history questionnaire, Pelvic Floor Distress Inventory-20 (PFDI-20) questionnaire, clinical examination. Demographic, medical/midwifery questionnaire composed of 25 question about age, menopause duration, number of pregnancies, last delivery mode, and systematic disease like hypertension, diabetes and chronic caught. Weight and height were measured with standard method. Body mass index was calculated as weight $(\mathrm{kg}) /$ height $\left(\mathrm{m}^{2}\right)$ and categorized according to the World Health Organization classification as normal $\left(<25.0 \mathrm{~kg} / \mathrm{m}^{2}\right)$, over weight (25.1-29.9 $\left.\mathrm{kg} / \mathrm{m}^{2}\right)$, and obese $\left(\geq 30.0 \mathrm{~kg} / \mathrm{m}^{2}\right)$.

POP was determined through clinical examination using simplified POP-Q, such that participants were placed in lithotomy position and requested to perform the Valsalva maneuver. In this system, the hymenal remnant is taken as a fixed reference point, and prolapse is assessed accordingly, such that prolapse was considered as first stage if the lowest prolapsed part was $1 \mathrm{~cm}$ above the reference point. If prolapse descent to $1 \mathrm{~cm}$ above to $1 \mathrm{~cm}$ below the hymenal remnants defines to stage 2 . In the stage 3 prolapse point descends greater than $1 \mathrm{~cm}$ past the hymenal remnants during maximum push. This method is a practical and acceptable method which can replace to POP-Q [16].

We used of PFDI-20 questionnaire for assessment of incontinency and POP. It was already translated in Persian language by standard forward-backward method, Cronbach's alpha coefficient for each sub domain of PFDI-20 was more than 0.65 [17].

To assess the reliability of diagnosis of POP, 10 women were examined by first author and a gynecologist, after that, we calculated inter-rater reliability using by kappaCohen coefficient. 


\section{Data analysis}

Data were analyzed using by IBM SPSS software ver. 19 (IBM Corp., Armonk, NY, USA). Quantitative data were reported as mean \pm standard deviation (SD), and qualitative data were reported as frequency. For determining risk factors of UI/AI and POP we used of multivariate logistic regression with backward strategy, and in this part, data were reported as odds ratio and confidence interval. $P \leq 0.05$ considered as significant.

\section{RESULTS}

The present study was conducted between March 2016 and September 2017. Out of 393 women, met the inclusion criteria $86.5 \%$ ( 340 women) agreed to participate in the study. Participants' mean \pm SD age was 54.3 \pm 4.0 years; $99.4 \%$ were housewives, $89.9 \%$ were illiterate or had elementary education (less than 5 years formal education), and 204 cases (60.0\%) reported having an average income (Table 1). The prevalence of SI was $50.9 \%$, UUI was $49.8 \%$, and AI was $15.6 \%$. One hundred eighty-seven participants (55.0\%) had one type of POP grade II or III.

Table 1. Sociodemographic and medical characteristics $(n=340)$

\begin{tabular}{lc}
\hline \multicolumn{1}{c}{ Characteristic } & $\mathrm{n}(\%)$ \\
\hline Age $(\mathrm{y})$ & $40(11.7)$ \\
$45-49$ & $132(38.8)$ \\
$50-54$ & $162(47.6)$ \\
$55-60$ & \\
Body mass index $\left(\mathrm{kg} / \mathrm{m}^{2}\right)$ & $41(12.05)$ \\
$<25.0$ & $106(31.1)$ \\
$25.1-29.9$ & $193(56.7)$ \\
$\geq 30.0$ & \\
Parity & $13(3.8)$ \\
$0-1$ & $107(31.5)$ \\
$2-4$ & $220(64.7)$ \\
$\geq 5$ & \\
Mode of recent delivery & $68(20.0)$ \\
Vaginal delivery with episiotomy & $203(59.7)$ \\
Vaginal delivery without episiotomy & $63(18.5)$ \\
Cesarean section & $26(7.6)$ \\
Exercise & $235(69.1)$ \\
Hot flash &
\end{tabular}

${ }^{a}$ Aerobic exercise/fast walking 10-30 minutes 3 times per weeks.
Table 2 shows frequency UI/AI and POP according to age groups.

\section{Binary logistic regression}

The multivariate analysis results showed that $2 \mathrm{nd}$ and 3rd degree prolapses are among risk factors for all types of incontinence, except for urge incontinence. Obesity is a risk factor for SI and UI. Other risk factors are also shown in Table 3.

\section{DISCUSSION}

The present study conducted on 340 healthy menopausal women for assessment of any types of incontinency and POP prevalence. The results showed that almost half of participants suffered from UI and POP. About 1 in 7 women reported AI. Prevalence of SI in our participants was slightly higher than UUI.

In a systematic review of 50 studies Milsom et al. [2] reported the prevalence of UI $1.8 \%$ to $30.5 \%$ among European and $1.5 \%$ to $15.2 \%$ among Asian populations. Schreiber Pedersen et al. [18] in a cross sectional study estimated that prevalence of UI among German and Danish women was about $45 \%$. Similar incontinency, the range of POP frequency is vary from 3\% to $54 \%$ [19].

It was difficult to compare the prevalence of POP and incontinency across the studies. Different methods for measurement as well as different population (according to age, sex, and comorbidities) are the most important causes of different results between the studies.

POP and incontinency are multifactorial. In line with other studies [19-21] we found several risk factors for them. Taken account to adjusted odds ratio, age and number of vaginal childbirths among the most significant risk factors of POP. With increasing 1 year, the odd of POP increases up to $10 \%$ as well as increasing every vaginal delivery leads to increasing odd of POP $4 \%$. Other risk factors of POP was including obesity and episiotomy. It should be noted that according to the nature of study design we could not distinguish episiotomy from perianal tears during vaginal delivery.

In line with other studies $[11,16]$. the present studies showed that UI/AI and POP have a common causes. POP was a remarkable risk factor for SI and AI. Gyhagen et al. [20] showed AI and UI were more seen in people with POP compared to those without. We found that obesity was risk factors of SI, UUI and POP and number of vaginal delivery was a risk factor for both SI 
Table 2. Prevalence of incontinences and POP according to age of participants

\begin{tabular}{lccc}
\hline \multirow{2}{*}{ Variable } & \multicolumn{3}{c}{ Age group $(\mathrm{y})$} \\
\cline { 2 - 4 } & $45-49(\mathrm{n}=42)$ & $50-54(\mathrm{n}=136)$ & $55-60(\mathrm{n}=161)$ \\
\hline UUI & $20(47.6)$ & $63(46.3)$ & $85(52.5)$ \\
SI & $22(52.4)$ & $66(48.5)$ & $85(58.5)$ \\
Al & $7(16.6)$ & $16(11.8)$ & $30(18.6)$ \\
POP anterior (grade II/III) & $22(52.3)$ & $53(39.0)$ & $83(51.2)$ \\
POP middle (grade II/III) & $15(35.7)$ & $33(24.2)$ & $60(37.2)$ \\
POP posterior (grade II/III) & $5(11.9)$ & $17(12.5)$ & $46(28.5)$ \\
\hline
\end{tabular}

Values are presented as number (\%).

POP: pelvic organ prolapse, UUl: urinary urgency incontinence, SI: stress incontinence, Al: anal incontinence.

Table 3. Multivariate regression model of risk factors of incontinences

\begin{tabular}{|c|c|c|c|c|}
\hline \multirow{2}{*}{ Risk factor } & \multicolumn{4}{|c|}{ Adjusted OR $(95 \% \mathrm{Cl}), P$ value } \\
\hline & $\mathrm{SI}$ & UUI & $\mathrm{Al}$ & POP \\
\hline POP & $5.07(2.71$ to 10.21$),<0.05$ & - & 2.92 (1.01 to 4.81$),<0.001$ & - \\
\hline Exercise & $-3.21(-1.12$ to -5.22$), 0.021$ & - & - & \\
\hline $\mathrm{BMI} \geq 30 \mathrm{~kg} / \mathrm{m}^{2}$ & 3.37 (2.11 to 8.32), 0.001 & 4.22 (2.91 to 10.32), 0.001 & - & 2.11 (1.21 to 3.67 ), 0.012 \\
\hline Hot flash & 2.37 (1.71 to 4.51 ), 0.034 & - & - & \\
\hline Age & - & - & - & 9.83 (6.51 to 14.48$),<0.001$ \\
\hline No. of vaginal delivery & - & - & - & $4.17(2.09$ to 8.72$), 0.001$ \\
\hline Episiotomy & - & - & 3.12 (2.01 to 5.22 ), 0.011 & $3.71(2.55$ to 7.34$), 0.012$ \\
\hline Diabetes & - & - & - & 2.01 (1.01 to 2.97 ), 0.037 \\
\hline
\end{tabular}

OR: odd ratio, Cl: confidence interval, SI: stress incontinence, UUl: urinary urgency incontinence, Al: anal incontinence, POP: pelvic organ prolapse, BMI: body mass index.

and POP.

In this study, exercise was protective factor against SI, which disagrees with the results obtained in a study by Shaw and Nygaard [22]. In a systematic review study, Bo et al. [23] concluded that there is no solid evidence for effectiveness of various types of exercise, such as breathing exercise, yoga, fitness, and Tai Chi yoga on UI. Yet, a study by Wu et al. [11] showed that lack of aerobic exercise increased UI and AI.

Hot flash was a risk factors for SI. Generally, the lack of estrogen is a risk factor for SI, and estrogen-therapy is an accepted treatment [24]. Therefore, it is acceptable to consider hot flash as a main sign of lack of estrogen and among predictors of SI.

There are some limitations in the present study. The study design was cross sectional. Probably we could not identified all risk factors of POP and UI/ AI according to the nature of study design.

This study was community base and participants re- cruited from healthy middle age women. It could be leads to avoid from overestimation of incontinency and POP frequency. The POP was identified both of questionnaire and clinical exam and this is another strength for our study.

The present study results showed that the prevalence of POP and UI and AI cannot be overlooked. It shows that women in middle age prefer to tolerate disorders especially disorders related with reproductive system.

Given the damaging effects of prolapse and incontinence on the quality of life and burden of the disease, assessment of POP and various incontinence in women, especially middle-age women should be on the agenda of family doctors and other health care providers in the primary health services system. Owing to present study results, the emphasis on modifiable risk factors including regular exercise, weight loss, should be considered. 


\section{CONFLICT OF INTEREST}

No potential conflict of interest relevant to this article was reported.

\section{ACKNOWLEDGMENTS}

This study was funded by Tabriz University of Medical Science (grant number: 5/4/4976).

\section{REFERENCES}

1. Berek JS, Novak E. Berek and Novak's gynecology. 15th ed. Philadelphia: Lippincott Williams \& Wilkins; 2012.

2. Milsom I, Coyne KS, Nicholson S, Kvasz M, Chen CI, Wein AJ. Global prevalence and economic burden of urgency urinary incontinence: a systematic review. Eur Urol 2014; 65: 79-95.

3. Hinkle JL, Cheever KH. Brunner \& Suddarth's textbook of medical-surgical nursing. 13th ed. Philadelphia: Lippincott Williams \& Wilkins; 2014.

4. Haylen BT, de Ridder D, Freeman RM, Swift SE, Berghmans B, Lee J, et al. An International Urogynecological Association (IUGA)/International Continence Society (ICS) joint report on the terminology for female pelvic floor dysfunction. Int Urogynecol J 2010; 21: 5-26.

5. Meschia M, Buonaguidi A, Pifarotti P, Somigliana E, Spennacchio M, Amicarelli F. Prevalence of anal incontinence in women with symptoms of urinary incontinence and genital prolapse. Obstet Gynecol 2002; 100: 719-23.

6. Jokhio AH, Rizvi RM, Rizvi J, MacArthur C. Urinary incontinence in women in rural Pakistan: prevalence, severity, associated factors and impact on life. BJOG 2013; 120: 180-6.

7. Waetjen LE, Ye J, Feng WY, Johnson WO, Greendale GA, Sampselle CM, et al. Association between menopausal transition stages and developing urinary incontinence. Obstet Gynecol 2009; 114: 989-98.

8. Hakimi S, Simbar M, Ramezani Tehrani F. Perceived concerns of azeri menopausal women in Iran. Iran Red Crescent Med J 2014; 16: e11771.

9. Yip SO, Dick MA, McPencow AM, Martin DK, Ciarleglio MM, Erekson EA. The association between urinary and fecal incontinence and social isolation in older women. Am J Obstet Gynecol 2013; 208: 146.e1-7.

10. Bliss DZ, Norton C, Vodusek DB. Raising awareness about fecal incontinence. Neurourol Urodyn 2010; 29: 612-5.

11. Wu JM, Matthews CA, Vaughan CP, Markland AD. Urinary, fe$\mathrm{cal}$, and dual incontinence in older U.S. Adults. J Am Geriatr Soc 2015; 63: 947-53.
12. Demir N, Yuruyen M, Atay K, Yavuzer H, Hatemi I, Doventas A, et al. Prevalence of fecal incontinence and associated risk factors in elderly outpatients: a cross-sectional study. Aging Clin Exp Res 2017; 29: 1165-71.

13. Elbiss HM, Osman N, Hammad FT. Prevalence, risk factors and severity of symptoms of pelvic organ prolapse among Emirati women. BMC Urol 2015; 15: 66.

14. Horst W, do Valle JB, Silva JC, Gascho CLL. Pelvic organ prolapse: prevalence and risk factors in a Brazilian population. Int Urogynecol J 2017; 28: 1165-70.

15. Terauchi M, Hirose A, Akiyoshi M, Owa Y, Kato K, Kubota T. Prevalence and predictors of storage lower urinary tract symptoms in perimenopausal and postmenopausal women attending a menopause clinic. Menopause 2015; 22: 1084-90.

16. Manonai J, Mouritsen L, Palma P, Contreras-Ortiz O, Korte JE, Swift S. The inter-system association between the simplified pelvic organ prolapse quantification system (S-POP) and the standard pelvic organ prolapse quantification system (POPQ) in describing pelvic organ prolapse. Int Urogynecol J 2011; 22: 347-52.

17. Hakmi S, Hajebrahimi S, Bastani P, Aminian E, Ghana S, Mohammadi M. Translation and validation of the pelvic floor distress inventory short form (PFDI-20), Iranian version. BMJ Open 2017; 7(Suppl 1): A76-7.

18. Schreiber Pedersen L, Lose G, Høybye MT, Elsner S, Waldmann A, Rudnicki M. Prevalence of urinary incontinence among women and analysis of potential risk factors in Germany and Denmark. Acta Obstet Gynecol Scand 2017; 96: 939-48.

19. Walker GJ, Gunasekera P. Pelvic organ prolapse and incontinence in developing countries: review of prevalence and risk factors. Int Urogynecol J 2011; 22: 127-35.

20. Gyhagen M, Bullarbo M, Nielsen TF, Milsom I. Prevalence and risk factors for pelvic organ prolapse 20 years after childbirth: a national cohort study in singleton primiparae after vaginal or caesarean delivery. BJOG 2013; 120: 152-60.

21. Fritel X, Varnoux N, Zins M, Breart G, Ringa V. Symptomatic pelvic organ prolapse at midlife, quality of life, and risk factors. Obstet Gynecol 2009; 113: 609-16.

22. Shaw JM, Nygaard IE. Role of chronic exercise on pelvic floor support and function. Curr Opin Urol 2017; 27: 257-61.

23. Bo K, Fernandes ACNL, Duarte TB, Brito LGO, Ferreira CHJ. Is pelvic floor muscle training effective for symptoms of overactive bladder in women? A systematic review. Physiotherapy 2020; 106: 65-76.

24. Castellani D, Saldutto P, Galica V, Pace G, Biferi D, Paradiso Galatioto G, et al. Low-dose intravaginal estriol and pelvic floor rehabilitation in post-menopausal stress urinary incontinence. Urol Int 2015; 95: 417-21. 